\title{
Meet Researcher in the Real World Using the ConAR: Context-Aware Researcher
}

\author{
Sung-Wook Baek, Jong-Hoon Seo, and Tack-Don Han \\ Dept. of Computer Science, Yonsei University, \\ 134, Seodaemun-Gu, Seoul, 120-749, Republic of Korea \\ \{yoshiboarder, jonghoon. seo, hantack\}@msl.yonsei.ac.kr
}

\begin{abstract}
In this paper, we focused on a research on a Location-Based Social Network Service to increase social interactions among people who are engaging in research and development. Since existing many of location-based social network services have only provided information of regions and social relations of users have targeted an unspecific majority of groups, they could not have active interactions, compared to users of online communities who have particular use purposes. ConAR what we designed to get over these weaknesses, aims at researches to academically exchange with others and it enables them to have social interactions with people of the same interests by helping them select discussion topics and decide assignment places simply and on impulse.
\end{abstract}

Keywords: Social Computing, Social Interaction, Location-Based Service, Context-Aware Service, Communities, Human Computer Interaction.

\section{Introduction}

Social Networking Service is useful to not only keep friendships with acquaintances, but also make new relationships. Because it is an online service, it is also possible to keep friendships with friends who live far away using this. This service is gradually developing into a variety of forms. For example, Twitter is now used to get news or information useful for life and Academia or Research Gate provides services like theses or projects of researchers for users for an academic exchange. In addition, Location-Based Social Networking Services using location information have been developed with an invention of Smart-phone.

In particular, Location-Based Social Networking Service provides not only information of regions like restaurants and transportation, but social networking functions among people who live in the same regions. In spite of these services, however, it is not easy to make social relations with people who have common interests and social networking doesn't work as actively as online community services, because it still aims at an unspecific majority of people.

The following scenarios suggest problems of the current Social Networking Services: Sung-Wook in a graduate school has a lot of interests in HCI. He opens research achievements and projects of named researchers in the HCI field and exchanges messages with them using an online Social Networking Service provided 
on Academia. One day, Sung-Wook participated in an academic conference held in COEX, Seoul to make a presentation of his thesis. He wanted to discuss with people who are interested in SNS like him, so tried to find them through his Location-Based Social Networking Service, but it was not easy for him to go forward and speak to them, because only a minority of people had interests in it and he had no idea of their research achievements and participation purposes in the conference.

Here, we can extract two main problems from the above examples. Firstly, many of the current social networking services including Academia cannot be practically used for discussion in a conference or office or laboratory. Secondly, they don't provide social networking services for an academic exchange of users.

ConAR has three characteristics as following. Firstly, it shows profiles and research performances of researchers around users based on their locations. Here, we designed it to help users search information what they really want by extracting information required for cooperation of researchers through a survey targeting researchers of companies and schools. Secondly, users can do online or offline social interactions, because it provides them with Contextual Information of participation possibility in offline meetings or meeting places where they prefer. Lastly, using 'ConAR', users can choose discussion topics by themselves and decide assignment places simply and promptly.

\section{Methods}

To induce necessary information and functions for ConAR service, we performed a survey regarding 17 professional $R \& D$ researchers in graduate school and company. Based on such result, we induced necessary personal information and service to have scholarly exchange, and by using rapid prototyping tool, we designed UX of ConAR. Finally, to estimate the usefulness and usability of ConAR, we realized using Android SDK. For the estimation, we invited 12 researchers, and they belong to graduate school and company R\&D center. The reason for limiting job like this is because the purpose of using ConAR is scholarly exchange in academy, school, or company, and actually, as a result of analyzing the job of academy participants, it was classified mainly as student, professor, and company researcher. 12 researchers were divided into 2 groups in 6 people, and those with no daily friendly relationship were chosen to estimate whether social interaction using ConAR is held well.

\subsection{Personal Information}

Regarding personal information related to users, survey was made based on the information opened in Korea's graduate school R\&D room, and 17 professionals participated in it. Table 1 is a survey investigation result regarding personal information of researchers needed for scholarly exchange.

Through Table 1 we could largely check two kinds of information. Firstly, the answer that Social Networking Service is needed in scholarly exchange was 3.7 in average, so it could be checked that it was positive. Secondly, regarding the most important thing in scholarly exchange, F. Consider the area of research was 4.2 in average and it was the highest, and I. Consider the project was 3.9 in average, and J. Consider the experience of field was 3.8 in average in the greatest order. 
Table 1. The result of survey about researcher's information for academical interaction

\begin{tabular}{|c|c|c|c|c|}
\hline Number & Attribute & Evaluation Tool & Average & $\begin{array}{l}\text { Response } \\
\text { Rate }\end{array}$ \\
\hline 1 & $\begin{array}{l}\text { Do you consider using SNS for the } \\
\text { academic interaction? }\end{array}$ & $\begin{array}{l}\text { Negative } 12345 \\
\text { Positive }\end{array}$ & 3.7 & $93.7 \%$ \\
\hline 2 & $\begin{array}{l}\text { What kind of researcher's } \\
\text { information do you consider when } \\
\text { you do the academic interaction? }\end{array}$ & & & \\
\hline A & Consider the degree & $\begin{array}{l}\text { Negative } 12345 \\
\text { Positive }\end{array}$ & 3.1 & $100 \%$ \\
\hline B & Consider the personality & $\begin{array}{l}\text { Negative } 12345 \\
\text { Positive }\end{array}$ & 3.5 & $100 \%$ \\
\hline $\mathrm{C}$ & Consider the advisor & $\begin{array}{l}\text { Negative } 12345 \\
\text { Positive }\end{array}$ & 3.5 & $100 \%$ \\
\hline $\mathrm{D}$ & Consider the paper (Journal) & $\begin{array}{l}\text { Negative } 12345 \\
\text { Positive }\end{array}$ & 3.5 & $100 \%$ \\
\hline $\mathrm{E}$ & Consider the sex & $\begin{array}{l}\text { Negative } 12345 \\
\text { Positive }\end{array}$ & 1.8 & $100 \%$ \\
\hline $\mathrm{F}$ & Consider the area of research & $\begin{array}{l}\text { Negative } 12345 \\
\text { Positive }\end{array}$ & 4.2 & $100 \%$ \\
\hline G & Consider the social position & $\begin{array}{l}\text { Negative } 12345 \\
\text { Positive }\end{array}$ & 2.5 & $100 \%$ \\
\hline $\mathrm{H}$ & Consider the lab & $\begin{array}{l}\text { Negative } 12345 \\
\text { Positive }\end{array}$ & 3.0 & $100 \%$ \\
\hline I & Consider the project & $\begin{array}{l}\text { Negative } 12345 \\
\text { Positive }\end{array}$ & 3.9 & $100 \%$ \\
\hline $\mathrm{J}$ & Consider the experience of field & $\begin{array}{l}\text { Negative } 12345 \\
\text { Positive }\end{array}$ & 3.8 & $100 \%$ \\
\hline
\end{tabular}

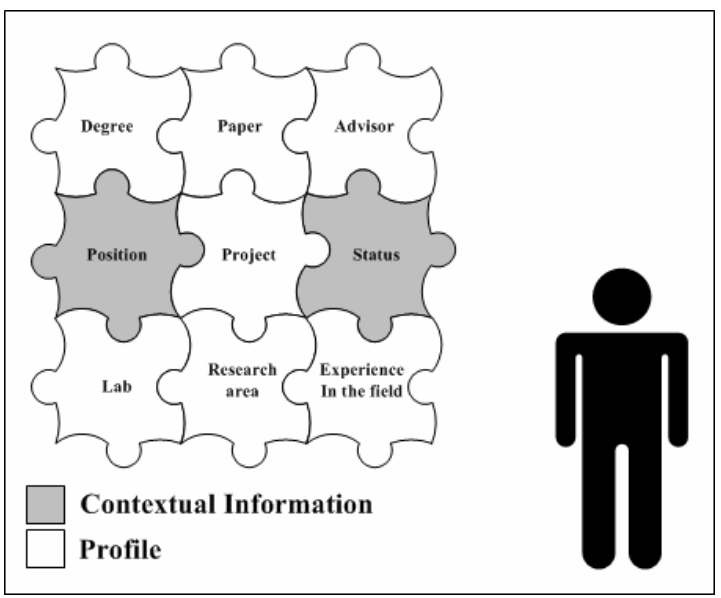

Fig. 1. Personal Information of ConAR 
Contrarily, regarding scholarly exchange, what is not important was E. Consider the sex with 1.8 in average which is the lowest, and G. Consider the social position was 2.5 in average which the second lowest. We, through this result, made the Personal Information which will be used in ConAR as in Fig 1.

Looking at Fig 1, not only personal information of investigated researcher, but also location of researcher, current status information, and meeting places they liked were also included. Researchers' personal information is data which is very much needed when searching for the people one wants have scholarly exchange through ConAR, and meeting place they like or current status of the self (in the paper, we will write this information as Contextual Information) and location information are data which is needed for meeting to be held in the real world.

In the information above, information like Contextual Information can be a problem related to privacy invasion. So, we provide Privacy protection function which can protect location of the self and status information for researchers. In case this function is activated, Contextual Information of the self can be opened, and in case of not activated status, no such Contextual Information is opened.

\subsection{Service}

To analyze necessary service for scholarly exchange, we also held survey regarding service during the survey in the above. We classified the items regarding service into 5 kinds, and we made the survey so that necessary 3 kinds in the greatest order could be answered. Table 2 is the following result.

Table 2. The result of survey about service for academical interaction

\begin{tabular}{|c|c|c|c|c|}
\hline Number & Attribute & Preference Service & & \\
\hline 3 & $\begin{array}{l}\text { Researcher } \\
\text { management }\end{array}$ & Researcher search & $\begin{array}{l}\text { Researcher } \\
\text { registration }\end{array}$ & $\begin{array}{l}\text { Researcher } \\
\text { management }\end{array}$ \\
\hline 4 & Communication ability & Sending a note & $\begin{array}{l}\text { Conversation } \\
\text { request }\end{array}$ & $\begin{array}{l}\text { Opening the } \\
\text { Community }\end{array}$ \\
\hline 5 & $\begin{array}{l}\text { Individual information } \\
\text { protection function }\end{array}$ & $\begin{array}{l}\text { Conversation } \\
\text { rejection }\end{array}$ & $\begin{array}{l}\text { Profile } \\
\text { management }\end{array}$ & $\begin{array}{l}\text { Share my } \\
\text { status }\end{array}$ \\
\hline 6 & $\begin{array}{l}\text { Research material } \\
\text { management function }\end{array}$ & Paper search & File sending & $\begin{array}{l}\text { Cooperation } \\
\text { service }\end{array}$ \\
\hline 7 & $\begin{array}{l}\text { Location Based } \\
\text { Service function }\end{array}$ & Share the location & Map service & $\begin{array}{l}\text { Recommendation } \\
\text { for place of } \\
\text { appointment }\end{array}$ \\
\hline
\end{tabular}

As shown in Table 2, service which is needed for scholarly exchange is investigated by dividing it into 5 items. For example, the necessary function for researcher management service was preferred in the order of searching researcher, registering researcher, and managing researcher. Based on such result, we composed the service which will be provided in ConAR and realized necessary functions for these services. 


\subsection{Prototyping}

Based on the investigated survey result above, we designed UX of ConAR in the method of Paper Prototyping. To use ConAR at the first time, user registration course should be held, and the course is expressed in Fig 2.

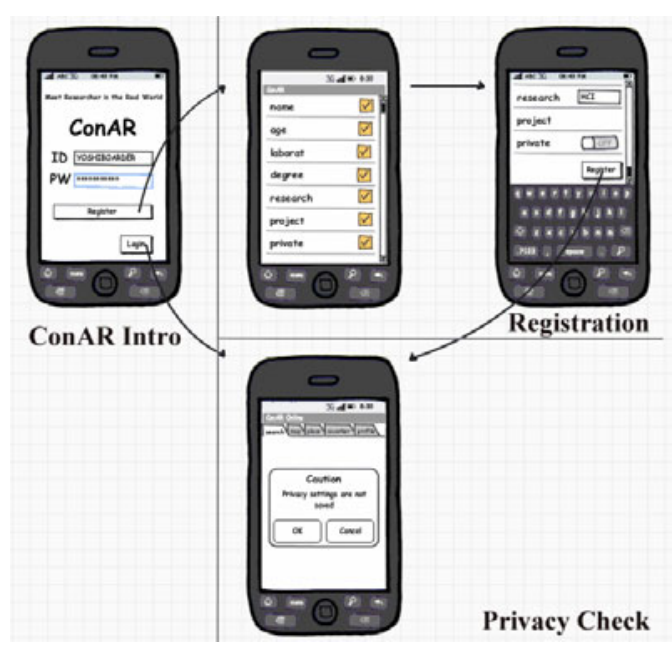

Fig. 2. User Registration Course Scenario

Because ConAR is a service based on location, personal privacy problem can occur. So, to previously prevent the problem, we composed a scenario as follows. Firstly, in case of using it for the first time, after user registration is held, Privacy function can be checked, and if it is Off, it will show an alert message so that no one would subconsciously open location information and status information. Even if a user is already registered, before starting ConAR service, the Privacy function is always checked and alert message is shown. Next is the scenario regarding searching researcher, MAP View, registering meeting place which is preferred, researcher management, personal profile management.

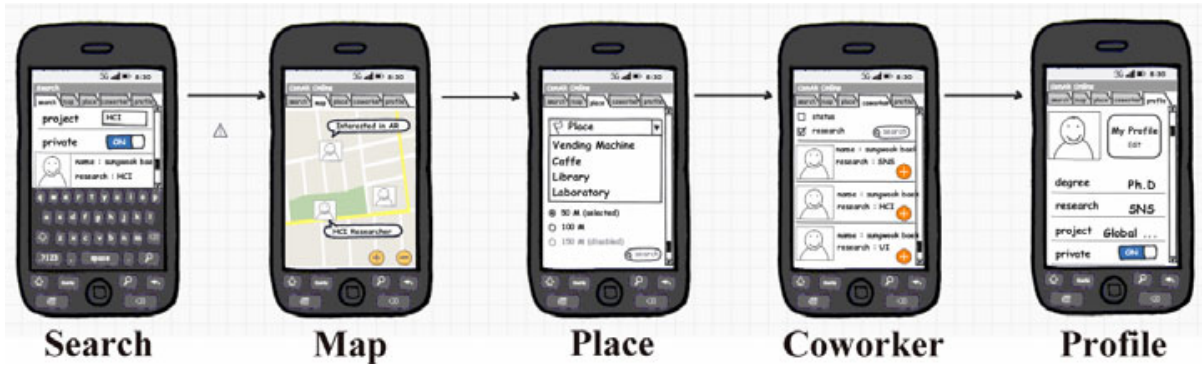

Fig. 3. ConAR's Scenario regarding Service 
To express each 5 kind of ConAR service in mobile environment, we designed a scenario as in Fig 3. Using tab controller, we designed User Interface, and explanation regarding each tab as follows. Firstly, in case of Research Tab, it provides searching for researcher to have scholarly exchange. For example, it shows related researcher by searching Paper, Project, or studying field. In case of Map Tab, it shows researchers around using ConAR service through Google Map. If Privacy mode in the Off state, it is not signed in the Map. In case of Place Tab, it searches preferred meeting place and provides registration function. Meeting place such as library, coffe shop, vending machine, and etc can be chosen, and based on the current location of the self, it searches the location by searching close place. In case of Coworker Tab, it shows the list of people who went through scholarly exchange (for example, when giving and taking message was held or conversation was held by real meeting) through ConAR. Also, if researcher is chosen, functions which can make scholarly exchange are provided. Finally, in case of Profile Tab, personal information of the self can be changed, and also, On/Off setting regarding Privacy can be done.

\subsection{Procedure}

In order to assess whether ConAR is helpful for an academic exchange of researchers, we conducted an experiment by dividing 12 participants into Group A and B consisting of six members separately. First of all, A group was organized with 4 of introvert people and 2 of active people, and it was observed if there was a social interaction among researchers by setting them to join a meeting actually in Contextual Information. On the contrary, B group was composed of 2 of introvert people and 4 of active people, and it was observed as well if there was a social interaction among them by setting them to be busy in Contextual Information.

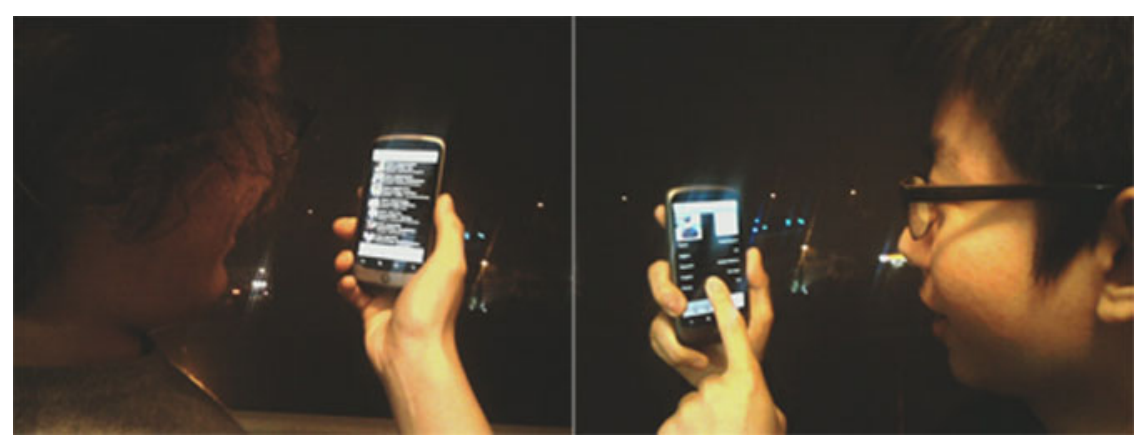

Fig. 4. Experimenter estimating usefulness and usability of ConAR service

\subsection{Results}

Fig 5 is a task process of ConAR that participants carried out. Although, Group A and $\mathrm{B}$ had equal processes in contacting researchers who they wanted to work with, using the Matching service of ConAR, the places for their social interaction were different between Group A and B depending on Contextual Information of researchers. For A group that was set to join the actual meeting in Contextual Information, participants 


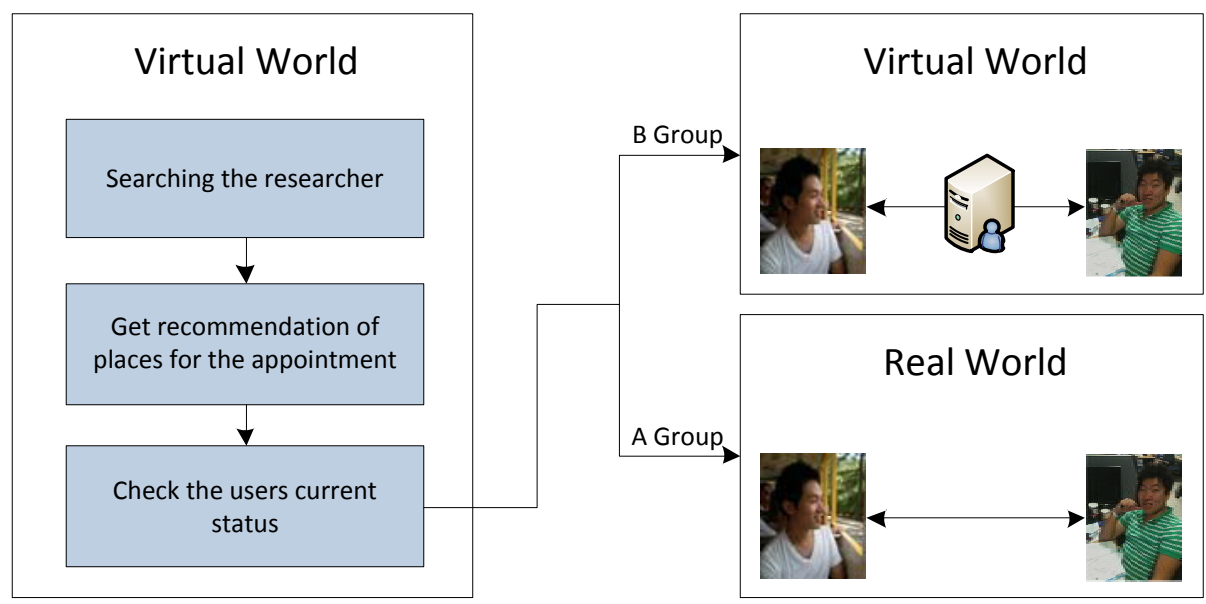

Fig. 5. Social interactions in the virtual world and the real world

had 5 total meetings actually out of 8 attempts, but for B group that was set to be busy in Contextual Information had 9 attempts, they had a total of 8 social interactions using a message delivery function online.

\section{Conclusion and Future Work}

We made participants have an academic exchange by carrying out a research on a location-based social networking service. ConAR connected researchers to other people who have the same interests to them through the Matching Function and made their academic exchange work smoothly in a conference or school or office by simplifying the process of the actual meeting. We also devised a social interaction considering the current conditions of researchers using Contextual Information. Lastly, we provided a location-based social networking service which is very useful for researchers based on online community, instant message delivery and User Management functions to keep their academic exchange continual.

In addition to this experiment, we will carry out a study on improvement of cooperation of researchers in the actual meeting. Although, existing Matching services have been developed to enable researchers that are motivated to meet the opponents, to cooperate with each other in the actual meeting, other services should be developed for an online social interaction. Therefore, we will develop services providing functions like brain storming, voice recording or video filming and white board used in discussion places.

\section{References}

1. Wang, F.-Y., Zeng, D., Carley, K.M., Mao, W.: Social Computing: From Social Informatics to Social Intelligence. IEEE Computer Society, Los Alamitos (2007)

2. Yamamoto, D., Takumi, I., Matsuo, H.: Location-Based Social Network Services Employing Student Cards for University. ACMGIS (2009) 
3. You, C.-W., Chen, Y.-L., Cheng, W.-H., Chen, M.-S., Sinica, A., Tsai, S.-A.: SocialCRC: A Social-and Context-Aware Rendezvous Coordination System. In: SIGCHI 2010 (2010)

4. Cummings, J.N., Butler, B., Kraut, R.: The Quality Of Online Social Relationships. Communications of the ACM (2002)

5. Zhao, D., Rosson, M.B.: How and Why People Twitter: The Role that Micro-blogging Plays in Informal Communication at Work. In: ACM 2009 International Conference on Supporting Group Work (2009)

6. Karimi, H.A., Zimmerman, B., Ozcelik, A., Roongpiboonsopit, D.: SoNavNet: A Framework for Social Navigation Networks. In: ACMGIS 2009 (2009) 